\title{
Comparative Analysis and Improvement of the 2-CSTRs Anaerobic Digestion System on Biofuel Production
}

\author{
Wan Song a , Li Yongfeng a,* \\ ${ }^{a}$ School of Forestry, Northeast Forestry University, Harbin 150040, China
}

\begin{abstract}
A 2-CSTRs anaerobic digestion system using molasses wastewater as a biochemical substrate for fermentative bioenergy production and substrate degradation under various ethanol recovery rates was developed. The effects of ethanol recovery rates (0\%-80\%) and organic loading rates (OLRs; 8,16 and $\left.24 \mathrm{kgCODm}^{-3} \mathrm{~d}^{-1}\right)$ on bioenergy production rate $\left(\varepsilon_{\mathrm{T}}\right)$ and bioenergy production yield were examined, respectively. Since the system produced a significant amount of biofuels (i.e. hydrogen, methane and ethanol), the process performance in terms of energy conversion derived from the combination of three biofuels was calculated according to production rates and combustion heat values. Recycle and reflux are the two reuse approaches for effluents in the system. A maximum HPR of $1.34( \pm 0.7) \mathrm{mol} \mathrm{d}^{-1}$ and a maximum EPR of $0.45( \pm 0.4) \mathrm{mol} \mathrm{d}^{-1}$ were observed at the OLR of $24 \mathrm{kgCOD} \mathrm{m}^{-3} \mathrm{~d}^{-1}$. Linear regression of the collection between HPR and EPR can be expressed as $\mathrm{y}=0.3182 \mathrm{x}+0.0114\left(\mathrm{r}^{2}=0.9853\right)$. The highest MPR of $0.45( \pm 0.07)$ mol d ${ }^{-1}$ was obtained at the original OLR of $24 \mathrm{kgCOD} \mathrm{m}^{-3} \mathrm{~d}^{-1}$, with an ethanol recover rate of $0 \%$. Recycle resulted to a higher $\varepsilon_{\mathrm{T}}$ and energy yield than reflux with the ethanol recover rate of $0 \%$ and $20 \%$, respectively. This was equal to the ethanol recover rate of $50 \%$, but lower than the ethanol recover rate of $80 \%$; indicating that recycle would be more feasible for lower ethanol recover rates, and reflux may be more suitable with other kinds of ethanol recover rates.
\end{abstract}

Keywords: continuous stirred tank reactor; two-phase anaerobic digestion system; substrate degradation rate; ethanol recovery rate; reuse approaches.

\section{Introduction}

With the development of the modern industry and the enormous consumption of energy sources, it is inevitable to look at cooperating in developing alternative non-conventional and renewable sources of energy ${ }^{[1]}$. Hydrogen, methane and ethanol have attracted a great deal of attention due to the high caloric value, recyclability and non-polluting nature of these sources ${ }^{[2]}$. As one of the main research objects of the technology area, bioenergy (biohydrogen, biomethane and bioethanol) production has gained wide attention. However, these biological methods have limitations. Take biohydrogen production as an example. Photobiological processes are limited by many practical and fundamental limitations ${ }^{[3]}$, and dark bacterial hydrogen fermentations have relatively low yields of hydrogen obtained with typically $10-30 \%$ of the substrate converted to hydrogen ${ }^{[4]}$. Therefore, improving bioenergy production yield and efficiency has been an area of emphases in the field of bioenergy production.

Anaerobic digestion technology is a bioenergy production method that not only allows bioenergy to be obtained, but also provides the extra benefit of treating organic waste ${ }^{[5,6]}$. Anaerobic digestion involves a commensal of two major types of bacteria flora: acidogenic bacteria, main hydrolyzes the substrates into hydrogen, carbon dioxide and short-chain volatile fatty acids (SCFAs); and methanogenic bacteria, converts metabolites from the acidogenic bacteria to methane ${ }^{[6]}$. For optimizing the growth of each type of bacteria, in 1971, Pohland and Ghoshhave proposed a hierarchical split-phase anaerobic digestion theory ${ }^{[7]}$. The two basic processes can partially be separated into a series of separate bioreactors ${ }^{[8]}$. The first reactor is for 
the acidogenic bacteria, while the second reactor is for methanogenic bacteria ${ }^{[8]}$. Hierarchical split-phase anaerobic digestion can be of some advantage in making the process more efficient to product renewable energy and more resistant to shock loading ${ }^{[9]}$. However, in earlier works on hierarchical split-phase anaerobic digestion, few measurements on simultaneous biofuel production have been reported in literature ${ }^{[10,11,12]}$. The fermentation pattern of the acidogenic phase is an important consideration for higher bioenergy production in a two-phase anaerobic digestion system. Fermentation types of the acidogenic phase mainly include the following: acetate-type, propionate-type, butyrate-type, and ethanol-type. For a long period, acetate-type fermentation has been depicted as the most common pathway in past surveys ${ }^{[13,14]}$. In the 1990s, the studies conducted by Ren et al. and $\mathrm{H}$. Wang et al. revealed that ethanol-type fermentation is the optimal pathway for fermentative hydrogen production by organic waste water. Ethanol-type fermentation is able to preserve the balance of $\mathrm{NADH}+\mathrm{H}^{+} / \mathrm{NAD}^{+}$, allowing the acidogenic fermentation process to be favorable for hydrogen production ${ }^{[15]}$. Since ethanol-type fermentation could produce a significant amount of biogas and liquid biofuels (i.e. hydrogen and ethanol), it is advisable that both hydrogen and ethanol can be recovered during the fermentation process, in order to realize additional economical benefits ${ }^{[16]}$. In previous studies, almost all researchers have focused on the recovery of only hydrogen or ethanol during the fermentation process, which resulted in low levels of energy production rate ${ }^{[4,17]}$. However, the production of hydrogen, ethanol and methane may be superior in producing biofuel. Previous works on continuous operation studies have revealed the mechanism and optimal parameters for biogas production, and insufficient information is available on biological energy production from molasses in a mixed microbial community culture ${ }^{[10,11,18]}$.

In this study, energy production rate derived from the combination of biofuels was calculated according to combustion heat values. The performance of sequential biological energy production from molasses wastewater in the 2-CSTRs anaerobic digestion system at different organic loading rates (OLRs) was examined. The energy production rate $\left(\varepsilon_{\mathrm{T}}\right)$ and substrate degradation rate (SDR) of the system can be dug. Due to the beneficial impact on methane production and the dual recovery of two of the most important biofuels (hydrogen and ethanol), ethanol-type fermentation was employed by controlling a number of parameters such as OLR, oxidation reduction potential (ORP), hydraulic retention time (HRT) and temperature ${ }^{[19,20]}$ in the acidogenic phase.

\section{Material and Methods}

\subsection{Experimental Apparatus}

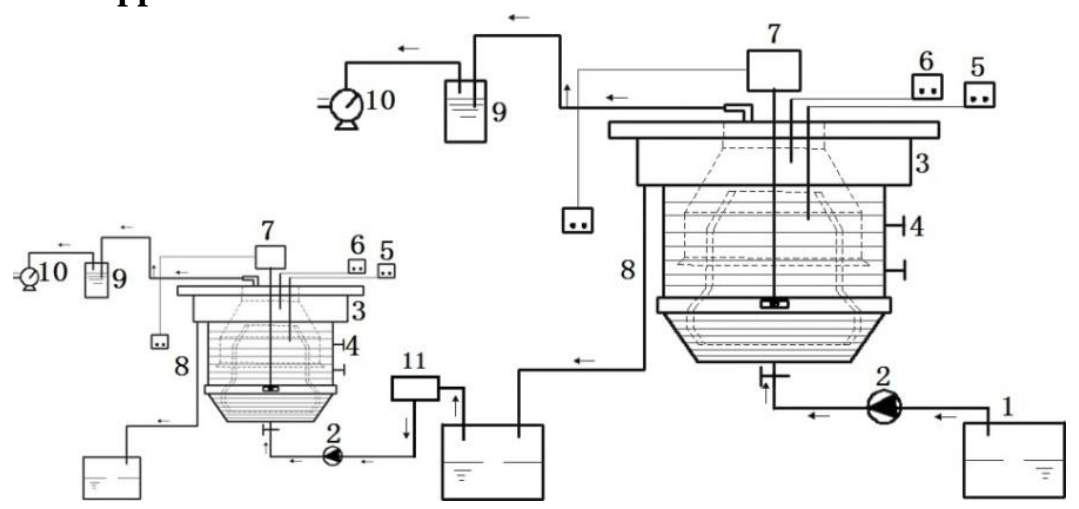

(1) Waste water box (2) Feed pump (3) Reactor (4) Water valve (5) thermometer

(6) ORP detector (7) Agitator (8) Conduit (9) Water lock (10) Biogas meter (11) Water bath

Fig.1 Schematic diagram of 2-CSTRs anaerobic digestion system 
The continuous stirred tank reactor (CSTR) was sealed to assure anaerobic condition. The reactor was made of hard PVC plastic with a gas-liquid-solid separating device installed inside the CSTR, in order to promote the retention of sludge. This was operated in continuous flow mode. Since the HRT of the hydrogen production phase was $1 / 4$ of the methane production phase, the experimental anaerobic digestion system (Fig. 1) comprised of a 5 L CSTR for hydrogen-production reactor (HyCSTR) and a 20 L CSTR for the methane-production reactor (MeCSTR). Before feeding into the MeCSTR, the effluent of the HyCSTR would be recycled to recover ethanol in the metabolites of the acidogenic bacteria; and the MeCSTR effluent goes back to the MeCSTR for recycling. The temperatures of both reactors were automatically maintained at $(35 \pm 1)^{\circ} \mathrm{C}$ using electric jackets around the reactors outside, and the substances were completely mixed by a constant speed stirred with a gear shift. The influent flow rates were controlled by feed pumps to regulate the HRTs and OLRs in the reactors. The generated biogas was collected with a water-lock and measured by a wet gas meter.

\subsection{Sludge and Feeding}

The seed sludge in the system was collected from a secondary settling tank in a local municipal wastewater treatment plant in Harbin. A $0.5 \mathrm{~mm}$ in diameter mesh was used to eliminate large particulate materials that could cause pump failure. The HyCSTR sludge was aerated and fed with molasses in batches and incubated at room temperature for 30 days to inhibit methanogen activity, and the MeCSTRs sludge was unaerated and fed with the same molasses. After cultivating, the sludge with suspended solids (SS) of $19.88 \mathrm{~g} / \mathrm{L}$ and volatile suspended solids (VSS) of $12.37 \mathrm{~g} / \mathrm{L}$ was inoculated into the HyCSTR; and the sludge with SS of $17.62 \mathrm{~g} / \mathrm{L}$ and VSS of $11.03 \mathrm{~g} / \mathrm{L}$ was inoculated into the MeCSTRs.

The molasses used in this study was collected from a local beet sugar refinery. Molasses that contain a high concentration of carbohydrates including sugars was diluted by water to a certain concentration. The COD: N: P was maintained at a ratio of 100:5:1 by adding synthetic fertilizer, in order to supply microorganisms with adequate nitrogen and phosphorus ${ }^{[21]}$.

\subsection{Operating conditions}

After the sludge was inoculated into reactors, the HyCSTR was operated in continuous mode by supplying the designed synthetic wastewater at HRT of six hours with OLRs of 8, 16 and 24 $\operatorname{kgCOD~} \mathrm{m}^{-3} \mathrm{~d}^{-1}$, respectively. MeCSTRs were operated in continuous mode by supplying the effluent of HyCSTRs at HRT of 24 hours. Before feeding these into the MeCSTR, the effluent of the HyCSTR would be recycled to recover ethanol in the metabolites of acidogenic bacteria; and the MeCSTR effluent was sent back to the MeCSTR for recycling. Ethanol recover rates were 0\%, $20 \%, 50 \%$ and $80 \%$, respectively.

\subsection{Analytical Methods}

COD, $\mathrm{pH}$, ORP, biogas yield and its constituents were measured and monitored daily in this study. COD was determined using a chemical oxygen-consumption measurer (Model LH-3BA; Beijing Lianhua Tech Co. Ltd., Beijing, China), while pH and ORP were determined using a combo detector (Model EP 366; Guangzhou Baonuo Co. Ltd., Guangzhou, China).

Biogas yield was measured at room temperature using a wet gas meter (Model LML-1; Changchun Filter Co. Ltd., Changchun, China), while its constituents were analyzed using SC- II gas chromatography equipped with a tube for collecting the gas sample from exportation. The gas chromatography was equipped with a thermal conductivity detector (TCD) and a stainless steel column filled with $2 \mathrm{~m}$ of Porapak Q (60-80 meshes). Nitrogen was used as the carrier gas at a 
flow rate of $70 \mathrm{ml} / \mathrm{min}$. The operational temperature for the column oven and detector is $150^{\circ} \mathrm{C}$. The sample was injected at a dose of $0.5 \mathrm{ml}$ each time. The hydrogen yield could be calculated based on the percentage of hydrogen in the biogas.

Detection of SCFAs in the fermentation solution was analyzed by another gas chromatograph (GC112; Shanghai Anal. Inst. Co.) using a flame ionization detector (FID). A 2-m stainless steel column was packed with the supporter GDX-103 (60-80 meshes). The temperatures of the injection port, oven and detector was $220^{\circ} \mathrm{C}, 190^{\circ} \mathrm{C}$, and $220^{\circ} \mathrm{C}$, respectively. The carrier gas was also nitrogen at a flow rate of $30 \mathrm{ml} / \mathrm{min}$.

\section{Results and Discussion}

\subsection{Hydrogen and ethanol production}

Hydrogen production rate (HPR, mol d ${ }^{-1}$ ) and ethanol production rate (EPR, mol d $\mathrm{d}^{-1}$ ) have generally been regarded as important indices to evaluate these biohydrogen producing processes. Figure 2 reveals the profile of HPR, hydrogen content (HC, \%) EPR, and ethanol content (EC, \%) with increasing OLRs. OLR significantly affected the production rate and content of hydrogen and ethanol from HyCSTR. The maximum HPR of $1.34( \pm 0.7)$ mold $^{-1}$ and the maximum EPR of 0.45 $( \pm 0.4) \mathrm{mol} \mathrm{d}^{-1}$ were observed at a OLR of $24 \mathrm{kgCOD} \mathrm{m}^{-3} \mathrm{~d}^{-1}$. Furthermore, the maximum $\mathrm{HC}$ of $26.17( \pm 3.62) \%$ and the maximum EC of $32.43( \pm 3.97) \%$ were obtained at an OLR of $16 \mathrm{kgCOD}$ $\mathrm{m}^{-3} \mathrm{~d}^{-1}$. The collection between HPR and EPR can be observed from Figure 3, showing that HPR and EPR were generally proportionately correlated, irrespective of the different OLRs. Linear regression was expressed as $y=0.3182 x+0.0114\left(r^{2}=0.9853\right)$.

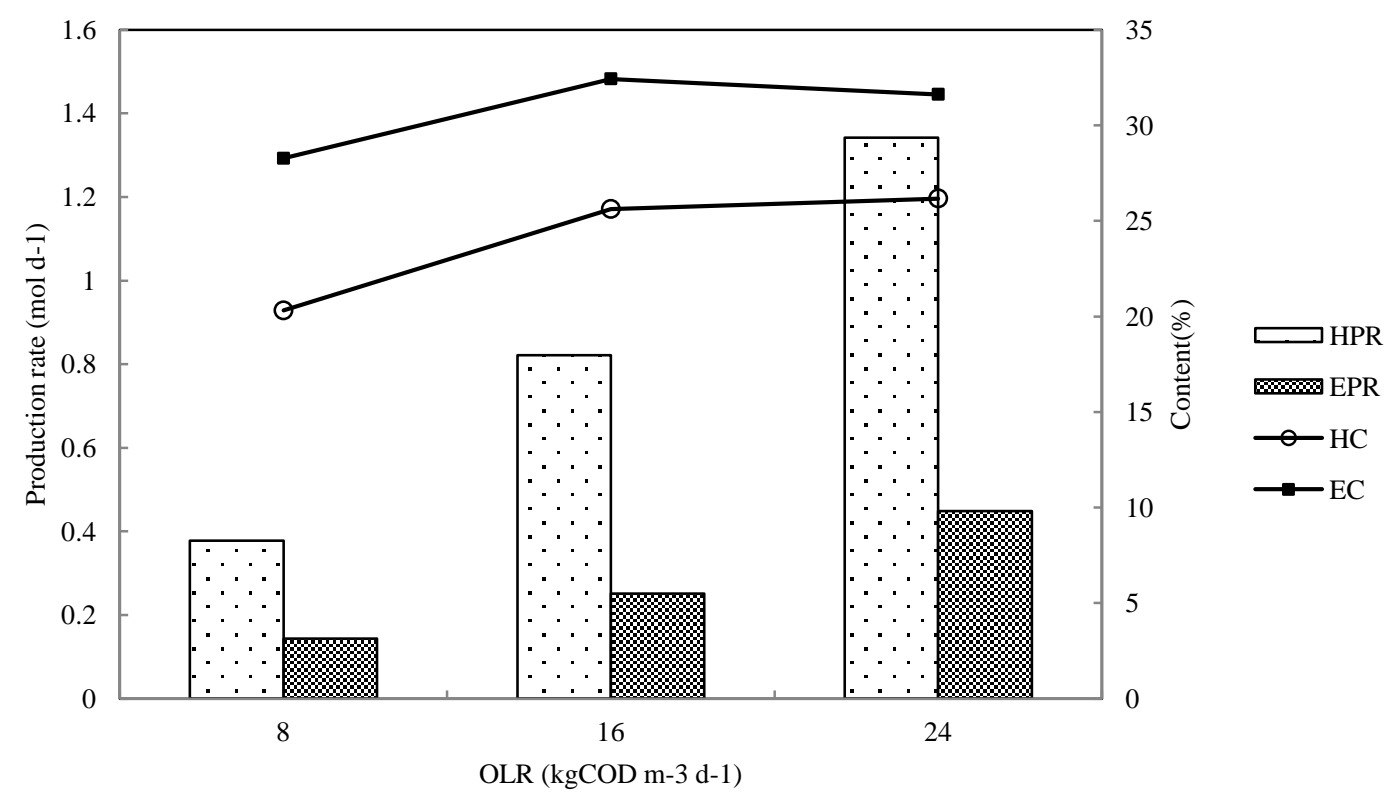

Fig.2 Performance of HyCSTR with respect to HPR, HC, EPR and EC 


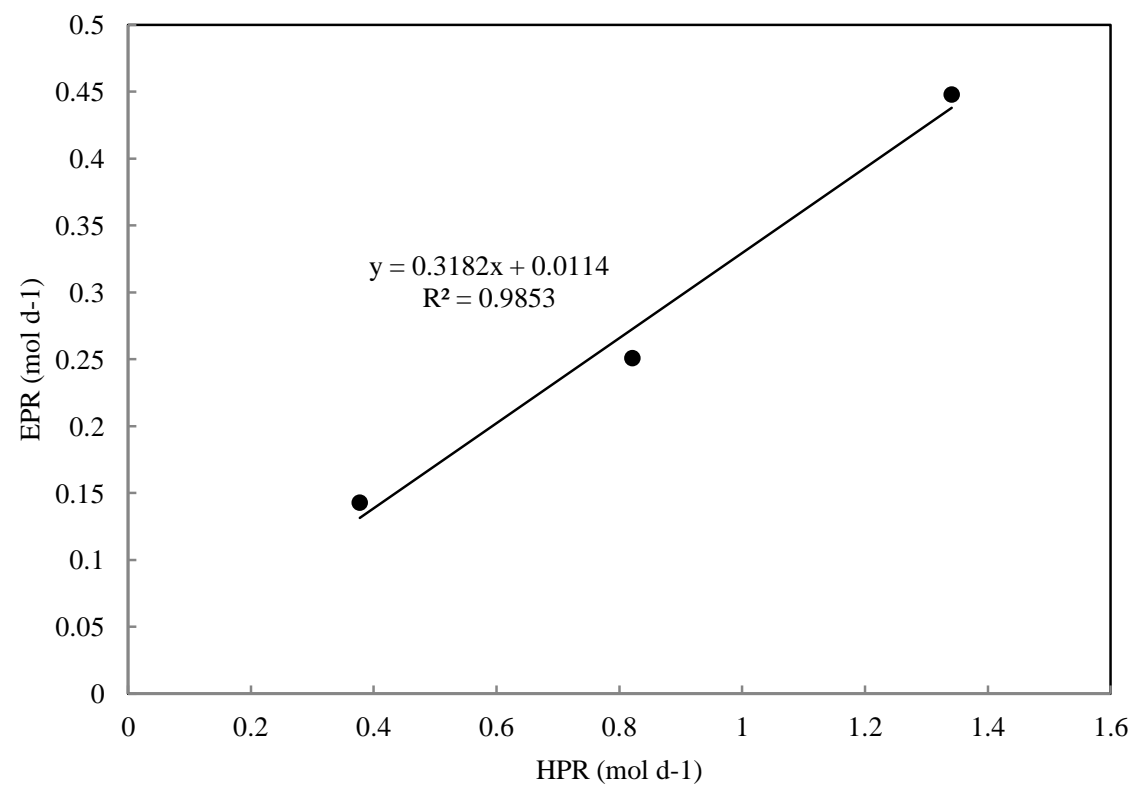

Fig.3 Collection between HPR and ethanol production rate

The performance of HyCSTR was evaluated for substrate degradation potential as COD removal rate $\left(\eta_{\mathrm{COD}}, \%\right)$ using Equation 1 . In this equation, $\mathrm{C}_{0}$ denotes the initial $\mathrm{COD}$ concentration $(\mathrm{mg} / \mathrm{L})$ of the influent and $\mathrm{C}_{\mathrm{T}}$ denotes the COD concentration $(\mathrm{mg} / \mathrm{L})$ of the outlet.

$\eta_{\mathrm{COD}}=\left[\left(\mathrm{C}_{0}-\mathrm{C}_{\mathrm{T}}\right) / \mathrm{C}_{0}\right] \times 100$

The substrate degradation rate (SDR, $\mathrm{kgCOD} \mathrm{m}^{-3} \mathrm{~d}^{-1}$ ) was calculated to study the pattern of hydrolysis yield, according to Equation 2.

$\mathrm{SDR}=\mathrm{OLR} \times \eta_{\mathrm{COD}}$

(2)

Table 1 HyCSTR performance during the whole process

\begin{tabular}{ccccc}
\hline HRT $(\mathrm{h})$ & OLR $\left(\mathrm{kgCOD} \mathrm{m}^{-3} \mathrm{~d}^{-1}\right)$ & $\mathrm{pH}$ & $\eta_{\mathrm{COD}}(\%)$ & $\mathrm{SDR}\left(\mathrm{kgCOD} \mathrm{m}^{-3} \mathrm{~d}^{-1}\right)$ \\
\hline 6 & 8 & 4.72 & $21.37( \pm 4.81)$ & $1.71( \pm 0.32)$ \\
6 & 16 & 4.43 & $25.14( \pm 4.32)$ & $4.24( \pm 0.39)$ \\
6 & 24 & 4.21 & $20.59( \pm 3.97)$ & $5.42( \pm 0.79)$ \\
\hline
\end{tabular}

Table 1 reveals the profile of SDR, $\eta_{\mathrm{COD}}$ and $\mathrm{pH}$ with increasing OLRs. The maximum SDR of $5.42( \pm 0.79) \mathrm{kgCOD} \mathrm{m}^{-3} \mathrm{~d}^{-1}$ was obtained at a OLR of $24 \mathrm{kgCOD} \mathrm{m} \mathrm{d}^{-1}$, and the maximum $\eta_{\text {COD }}$ of $25.14( \pm 4.32) \%$ was obtained at an OLR of $16 \mathrm{kgCOD} \mathrm{m}^{-3} \mathrm{~d}^{-1} \cdot \mathrm{pH}$ was also inspected during the operation in HyCSTR. It has been generally accepted that enzyme activity, metabolic pathway, and dominant species can all be directly affected by the $\mathrm{pH}$ value ${ }^{[22,26]}$. A pH around 5.5 has been reported as the optimal $\mathrm{pH}$ for biohydrogen production in treating glucose and rice winery wastewater on continuous operation studies ${ }^{[23]}$. In this study, the lowest $\eta_{\mathrm{COD}}$ occurred at a $\mathrm{pH}$ value of 4.2 (Table 1), and the highest $\eta_{\mathrm{COD}}$, EC and HC (Fig. 2 and Table 1) occurred at a pH value of 4.4; which was consistent with existing studies. No methane was detected in the biogas during the whole process, indicating that there might be an attribute to the low operational $\mathrm{pH}$ that could effectively block methanogenesis. This might be the reason for the relatively low substrate degradation efficiency observed in the acidogenic process.

\subsection{Methane production}

After the inoculation of the anaerobic mixed consortia, the MeCSTR was operated with the 
designed synthetic wastewater at an OLR of $8 \mathrm{kgCOD} \mathrm{m}^{-3} \mathrm{~d}^{-1}$ initially by adjusting the feed $\mathrm{pH}$ to a seven fora period of 37 days. Subsequently, the reactor was operated with effluent, which was recycled to recover ethanol in themetabolites of acidogenic bacteria generated from HyCSTR as feed. The process performance of the MeCSTR versus ethanol recovery rate was determined based on methane recovery, COD removal, and the methanogenic activity of the activated sludge. These results are shown in Table 2. Experimental data illustrates that the methane production rate (MPR, $\mathrm{mol} /$ day) gradually increased with increasing original OLRs, and decreased with an increasing ethanol recover rate. The highest MPR of $0.45( \pm 0.07) \mathrm{mol} \mathrm{d}^{-1}$ was obtained at the original OLR of $24 \mathrm{kgCOD} \mathrm{m} \mathrm{m}^{-3} \mathrm{~d}^{-1}$ with an ethanol recovery rate of $0 \%$. In spite of the diversiform ethanol recover rate, global $\eta_{\text {COD-M }}$ was above $46 \%$; which fluctuated at certain values in small range due to the stable function of the bacterial flora. However, when the ethanol recovery rate achieved $80 \%$, $\eta_{\text {COD-M }}$ showed a downward trend. After feeding soluble fermentative metabolite bound substrate, consistent decrease in SCFAs concentration observed with the experimental period in MeCSTR. As seen in Table.2, reduction in COD concentration in concurrence with the biogas production suggested the fact that the residual carbon source composed with SCFAs generated from HyCSTR had participated in methanogenic metabolic process.

Table 2 Performance of MeCSTR with different ethanol recovery rates

\begin{tabular}{cccccc}
\hline $\begin{array}{c}\text { Ethanol recover rate } \\
(\%)\end{array}$ & $\begin{array}{c}\text { Original OLR } \\
\left(\mathrm{kgCOD} \mathrm{m}^{-3} \mathrm{~d}^{-1}\right)\end{array}$ & $\begin{array}{c}\text { MPR } \\
\left(\mathrm{mol} \mathrm{d}^{-1}\right)\end{array}$ & $\begin{array}{c}\eta \\
(\%)\end{array}$ & $\begin{array}{c}\text { VSS } \\
\left(\mathrm{g} \mathrm{L}^{-1}\right)\end{array}$ & $\begin{array}{c}\text { VSS/SS } \\
(\%)\end{array}$ \\
\hline \multirow{2}{*}{0} & 8 & $0.182( \pm 0.07)$ & $50.1( \pm 3.22)$ & $13.15( \pm 1.27)$ & $63.22( \pm 3.29)$ \\
& 16 & $0.266( \pm 0.09)$ & $52.3( \pm 4.17)$ & $13.67( \pm 2.09)$ & $64.97( \pm 4.11)$ \\
20 & 8 & $0.448( \pm 0.13)$ & $52.1( \pm 3.25)$ & $15.52( \pm 1.92)$ & $65.87( \pm 3.07)$ \\
\hline \multirow{2}{*}{5} & $0.157( \pm 0.05)$ & $46.6( \pm 4.91)$ & $12.32( \pm 1.72)$ & $65.02( \pm 4.21)$ \\
& 16 & $0.234( \pm 0.11)$ & $51.3( \pm 5.11)$ & $13.07( \pm 2.07)$ & $63.69( \pm 5.13)$ \\
& 24 & $0.373( \pm 0.11)$ & $53.3( \pm 4.78)$ & $14.97( \pm 1.93)$ & $63.07( \pm 4.81)$ \\
\hline & 8 & $0.129( \pm 0.04)$ & $44.3( \pm 4.93)$ & $12.94( \pm 2.04)$ & $59.24( \pm 3.19)$ \\
& 16 & $0.211( \pm 0.07)$ & $46.9( \pm 4.72)$ & $11.69( \pm 2.01)$ & $61.88( \pm 4.35)$ \\
& 24 & $0.254( \pm 0.08)$ & $49.3( \pm 5.16)$ & $12.33( \pm 1.95)$ & $59.42( \pm 5.33)$ \\
\hline & 8 & $0.079( \pm 0.05)$ & $24.7( \pm 3.39)$ & $9.54( \pm 1.36)$ & $52.42( \pm 3.24)$ \\
& 16 & $0.117( \pm 0.08)$ & $27.5( \pm 3.53)$ & $8.77( \pm 1.29)$ & $50.08( \pm 4.98)$ \\
& 24 & $0.137( \pm 0.08)$ & $20.9( \pm 4.12)$ & $10.02( \pm 1.57)$ & $51.59( \pm 5.34)$ \\
\hline
\end{tabular}

The following equations are used for computing methanogenic fermentation balance consuming the hydrogen and SCFAs formed during the acidogenic process.

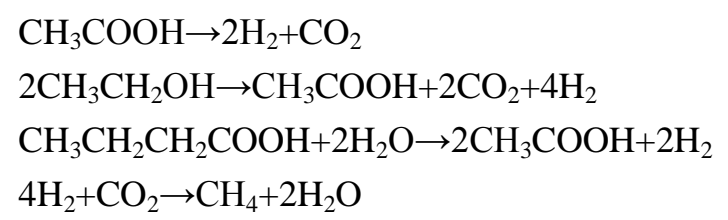

As depicted by these equations, the extractions of hydrogen and ethanol formed in the HyCSTR are essential for methane formation in the subsequent methanogenic step ${ }^{[23,29]}$. The lowest MPR and $\eta_{\text {COD-M }}$ obtained with an ethanol recoverry rate of $80 \%$ in this study may be attributed to two reasons. The first one is due to the extraction of ethanol and hydrogen generated from HyCSTR. The second reason might be that the methanogen activity was inhibited by acidophilic conditions attributed to the ethanol-recovery process. Optimum $\mathrm{pH}$ range for methanogenus activity was 
reported in a range of $6.0-7.5^{[25-33]}$, while the MeCSTR $\mathrm{pH}$ range was below 5.7. However, effluent $\mathrm{pH}$ revealed a gradual rise in $\mathrm{pH}$ values. This might be due to the metabolic process taken by the methanogen bacteria with respect to SCFAs in feeding. Shift of $\mathrm{pH}$ to basic conditions correlated well with the documented SCFAs consumption ${ }^{[34]}$. Samples during the course of experiments were analyzed for SCFAs composition viz., acetic acid (HAc) to butyrate ( $\mathrm{HBu}$ ), propionic acid ( $\mathrm{HPr}$ ) and ethanol (EtOH) to have understanding of the change in the metabolic pathway ${ }^{[35-39]}$. During methanogenic process in MeCSTR, composition of metabolites varied significantly. A marked variation in EtOH concentration was observed along with increase in HAc and $\mathrm{HPr}$ concentrations, and decrease in $\mathrm{HBu}$ (Table.3). The variation observed in soluble metabolites concentration suggested that of SCFAs was consumed under methanogenic microenvironment in the process of methane generation ${ }^{[40,41]}$.

Table 3 Concentrations of SCFAs of the MeCSTR

\begin{tabular}{|c|c|c|c|c|c|c|c|c|c|}
\hline \multirow{2}{*}{$\begin{array}{c}\text { Original OLR } \\
\left(\operatorname{kgCOD~m}^{-3} \mathrm{~d}^{-1}\right)\end{array}$} & \multirow{2}{*}{$\begin{array}{c}\text { EtOH } \\
\text { recover } \\
\text { rate }(\%)\end{array}$} & \multicolumn{2}{|c|}{$\begin{array}{c}\text { EtOH Proportion } \\
(\%)\end{array}$} & \multicolumn{2}{|c|}{$\begin{array}{l}\text { HAC proportion } \\
(\%)\end{array}$} & \multicolumn{2}{|c|}{$\begin{array}{l}\text { HBu proportion } \\
(\%)\end{array}$} & \multicolumn{2}{|c|}{$\begin{array}{l}\text { HPr proportion } \\
\qquad \%)\end{array}$} \\
\hline & & Influent & Effluent & Influent & Effluent & Influent & Effluent & Influent & Effluent \\
\hline \multirow{4}{*}{8} & 0 & \multirow{4}{*}{28.27} & 25.21 & \multirow{4}{*}{42.77} & 58.76 & \multirow{4}{*}{22.49} & 8.39 & \multirow{4}{*}{6.47} & 7.64 \\
\hline & 20 & & 22.54 & & 60.51 & & 8.74 & & 8.21 \\
\hline & 50 & & 16.33 & & 65.45 & & 9.65 & & 8.57 \\
\hline & 80 & & 8.83 & & 72.01 & & 10.24 & & 8.92 \\
\hline \multirow{4}{*}{16} & 0 & \multirow{4}{*}{32.43} & 27.52 & \multirow{4}{*}{49.84} & 61.01 & \multirow{4}{*}{13.85} & 7.3 & \multirow{4}{*}{3.88} & 4.17 \\
\hline & 20 & & 24.79 & & 63.99 & & 6.6 & & 4.62 \\
\hline & 50 & & 18.13 & & 69.69 & & 7.05 & & 5.13 \\
\hline & 80 & & 10.07 & & 77.03 & & 7.92 & & 4.98 \\
\hline \multirow{4}{*}{24} & 0 & \multirow{4}{*}{31.62} & 26.35 & \multirow{4}{*}{52.13} & 62.96 & \multirow{4}{*}{12.14} & 6.22 & \multirow{4}{*}{4.11} & 4.47 \\
\hline & 20 & & 23.58 & & 64.91 & & 6.99 & & 4.52 \\
\hline & 50 & & 17.11 & & 70.39 & & 7.47 & & 5.03 \\
\hline & 80 & & 9.11 & & 76.32 & & 9.56 & & 5.01 \\
\hline
\end{tabular}

The compositional ratio of metabolites formed during hydrogen and methane generation were often regarded as a significant indicator in evaluating the metabolic pathway of the biochemical process ${ }^{[27,41,43]}$. HAc and EtOH were the major metabolites observed, which indicate a good pathway for hydrogen production in the HyCSTR ${ }^{[39,42,43]}$, On the contrary, since HAC and EtOH are the main carbon sources for the methanogenic stage, and visible reduction in $\mathrm{HAC}$ and EtOH concentration were observed during the methanogenic process in this study. However, the effluent of the system continued to contain a certain amount of HAC and EtOH due to the incomplete reaction that resulted from the characteristics of the microorganism. The content of SCFAs in the effluent of the whole system is shown in Table 4. 
Table 4 Content of SCFAs of the system effluent

\begin{tabular}{cccc}
\hline $\begin{array}{c}\text { EtOH recover rate } \\
(\%)\end{array}$ & $\begin{array}{c}\text { Original OLR } \\
\left(\mathrm{kgCOD} \mathrm{m}^{-3} \mathrm{~d}^{-1}\right)\end{array}$ & $\begin{array}{c}\text { EtOH } \\
\left(\mathrm{mg} \mathrm{L}^{-1}\right)\end{array}$ & $\begin{array}{c}\text { HAC } \\
\left(\mathrm{mg} \mathrm{L}^{-1}\right)\end{array}$ \\
\hline 0 & 8 & $117.43( \pm 13.29)$ & $273.71( \pm 21.07)$ \\
& 16 & $241.46( \pm 27.62)$ & $543.17( \pm 49.82)$ \\
\hline 20 & 8 & $377.34( \pm 21.17)$ & $901.68( \pm 72.59)$ \\
\hline 50 & 16 & $99.31( \pm 7.66)$ & $266.54( \pm 27.62)$ \\
& 24 & $204.20( \pm 23.52)$ & $527.05( \pm 38.19)$ \\
& 8 & $319.12( \pm 29.81)$ & $878.46( \pm 43.33)$ \\
\hline 80 & 16 & $67.10( \pm 5.98)$ & $268.96( \pm 21.98)$ \\
& 24 & $137.97( \pm 9.09)$ & $530.22( \pm 41.24)$ \\
& 8 & $215.62( \pm 16.88)$ & $887.20( \pm 52.17)$ \\
\hline \multirow{2}{*}{5} & $43.61( \pm 5.24)$ & $355.44( \pm 19.83)$ \\
& 16 & $89.68( \pm 8.33)$ & $685.53( \pm 39.52)$ \\
\hline
\end{tabular}

\subsection{Bioenergy production of the system}

Considering the input and output ratio of energy, it was not necessary to recovery total residual ethanol. In this study, if the content of ethanol was less than $100 \mathrm{mg} / \mathrm{L}$, there was no need for ethanol recovery. If the content of ethanol was more than $250 \mathrm{mg} / \mathrm{L}$, the recovery rate was $60 \%$. In other cases, the recovery rate was $40 \%$. $\varepsilon_{\mathrm{T}}$ derived from the combination of three biofuels was calculated according to their production rate and combustion heat values $(Q, \mathrm{~kJ} / \mathrm{mol})$, which are shown in the following equations.

$$
\begin{aligned}
& \varepsilon_{\mathrm{H}}=\mathrm{HPR} \times Q_{\mathrm{H}} \\
& \varepsilon_{\mathrm{EtOH}}=\mathrm{EPR} \times Q_{\mathrm{EtOH}} \\
& \varepsilon_{\mathrm{M}}=\mathrm{MPR} \times Q_{\mathrm{M}} \\
& \varepsilon_{\mathrm{T}}=\varepsilon_{\mathrm{H}}+\varepsilon_{\mathrm{EtOH}}+\varepsilon_{\mathrm{M}}
\end{aligned}
$$

In addition, $\mathrm{Q}_{\mathrm{H}}=286 \mathrm{~kJ} / \mathrm{mol}, \mathrm{Q}_{\mathrm{EtOH}}=1366 \mathrm{~kJ} / \mathrm{mol}$, and $\mathrm{Q}_{\mathrm{M}}=890 \mathrm{~kJ} / \mathrm{mol}$.

Degradation yield of the organic substrate by the whole system was established with regard to OLR and the ethanol recovery rate during the steady state period of each reactor. SDR and $\eta_{\mathrm{COD}}$ are reported in Table 5, and performance of bioenergy production rate $\left(\varepsilon_{\mathrm{T}}, \mathrm{kJ} / \mathrm{day}\right)$ with different experiment conditions in the 2-CSTRs anaerobic digestion system can be observed in Table 6 .

The degradation yield of the organic substrate is based on microbiological activity, metabolic pathway, duration of the metabolic process, and occasionally, the area where the duration of the metabolic process is the highest and could not have the best ability for degradation yield. The experimental data revealed that the lowest SDR and $\eta_{\mathrm{COD}}$ was obtained when the system had no reuse approaches. However, the highest SDR and $\eta_{\mathrm{COD}}$ do not necessarily occur in recycle or reflux (Table 5). Generally, the reflux process can obtain a higher degradation yield of organic substrate, because it can degrade more kinds of organic matter, and the recycle process is just for ethanol. In practice, the accumulation of soluble microbial products (SMP) occurred in the system, and this caused the lower degrading efficiency. 
Table 5 SDR and $\eta_{\text {COD }}$ of 2-CSTRs system with different reuse approaches

\begin{tabular}{|c|c|c|c|c|c|c|c|}
\hline \multirow{2}{*}{$\begin{array}{c}\text { Recovery } \\
\text { rate } \\
(\%)\end{array}$} & \multirow{2}{*}{$\begin{array}{c}\text { OLR } \\
(\mathrm{kgCOD} \\
\left.\mathrm{m}^{-3} \mathrm{~d}^{-1}\right)\end{array}$} & \multicolumn{2}{|c|}{ No reuse } & \multicolumn{2}{|c|}{ Recycle } & \multicolumn{2}{|c|}{ Reflux } \\
\hline & & $\begin{array}{c}\text { SDR } \\
(\mathrm{kgCOD} \\
\left.\mathrm{m}^{-3} \mathrm{~d}^{-1}\right)\end{array}$ & $\begin{array}{c}\eta_{\mathrm{COD}} \\
(\%)\end{array}$ & $\begin{array}{c}\text { SDR } \\
(\mathrm{kgCOD} \\
\left.\mathrm{m}^{-3} \mathrm{~d}^{-1}\right)\end{array}$ & $\begin{array}{c}\eta_{\mathrm{COD}} \\
(\%)\end{array}$ & $\begin{array}{c}\text { SDR } \\
(\mathrm{kgCOD} \\
\left.\mathrm{m}^{-3} \mathrm{~d}^{-1}\right)\end{array}$ & $\begin{array}{c}\eta_{\mathrm{COD}} \\
(\%)\end{array}$ \\
\hline \multirow{3}{*}{0} & 8 & 4.75 & $59.38( \pm 3.11)$ & 5.21 & $65.13( \pm 2.21)$ & 5.02 & $62.75( \pm 2.53)$ \\
\hline & 16 & 9.58 & $59.88( \pm 2.97)$ & 11.08 & $69.25( \pm 2.17)$ & 10.16 & $63.51( \pm 2.99)$ \\
\hline & 24 & 14.58 & $60.75( \pm 3.62)$ & 16.76 & $69.84( \pm 2.17)$ & 15.14 & $63.08( \pm 2.76)$ \\
\hline \multirow{3}{*}{20} & 8 & 5.14 & $64.25( \pm 2.88)$ & 5.14 & $64.25( \pm 2.45)$ & 5.31 & $66.38( \pm 2.82)$ \\
\hline & 16 & 10.96 & $68.5( \pm 2.95)$ & 11.38 & $71.13( \pm 2.97)$ & 11.25 & $70.31( \pm 3.17)$ \\
\hline & 24 & 16.14 & $67.25( \pm 3.24)$ & 17.15 & $71.46( \pm 3.07)$ & 16.65 & $69.38( \pm 3.04)$ \\
\hline \multirow{3}{*}{50} & 8 & 5.7 & $71.25( \pm 3.79)$ & 5.41 & $67.63( \pm 2.99)$ & 5.62 & $70.25( \pm 2.83)$ \\
\hline & 16 & 12.51 & $71.19( \pm 4.52)$ & 11.82 & $73.75( \pm 3.89)$ & 11.61 & $72.56( \pm 4.05)$ \\
\hline & 24 & 16.96 & $70.67( \pm 4.03)$ & 17.78 & $72.54( \pm 3.25)$ & 17.78 & $74.08( \pm 3.74)$ \\
\hline \multirow{3}{*}{80} & 8 & 5.08 & $63.55( \pm 3.28)$ & 5.08 & $63.52( \pm 3.88)$ & 5.33 & $66.25( \pm 3.62)$ \\
\hline & 16 & 11.04 & $69.02( \pm 3.92)$ & 11.09 & $69.2( \pm 3.71)$ & 11.44 & $71.55( \pm 3.58)$ \\
\hline & 24 & 15.88 & $66.17( \pm 4.01)$ & 16.07 & $67.41( \pm 3.64)$ & 16.07 & $66.96( \pm 3.93)$ \\
\hline
\end{tabular}

Table 6 Bioenergy production of 2-CSTRs system with different reuse approaches

\begin{tabular}{|c|c|c|c|c|c|c|c|}
\hline \multirow{2}{*}{$\begin{array}{c}\text { Recovery } \\
\text { rate } \\
(\%)\end{array}$} & \multirow{2}{*}{$\begin{array}{c}\text { OLR } \\
(\mathrm{kgCOD} \\
\left.\mathrm{m}^{-3} \mathrm{~d}^{-1}\right)\end{array}$} & \multicolumn{2}{|c|}{ No reuse } & \multicolumn{2}{|c|}{ Recycle } & \multicolumn{2}{|c|}{ Reflux } \\
\hline & & $\begin{array}{c}\varepsilon_{T} \\
\left(\mathrm{~kJ} \mathrm{~d}^{-1}\right)\end{array}$ & $\begin{array}{c}\text { Energy } \\
\text { yield }(\mathrm{kJ} \\
\left.\mathrm{kgCOD}^{-1}\right)\end{array}$ & $\begin{array}{c}\varepsilon_{T} \\
\text { (kJ/day) }\end{array}$ & $\begin{array}{l}\text { Energy } \\
\text { yield }(\mathrm{kJ} \\
\left.\mathrm{kgCOD}^{-1}\right)\end{array}$ & $\begin{array}{c}\varepsilon_{T} \\
\left(\mathrm{~kJ} \mathrm{~d}^{-1}\right)\end{array}$ & $\begin{array}{l}\text { Energy } \\
\text { yield }(\mathrm{kJ} \\
\left.\mathrm{kgCOD}^{-1}\right)\end{array}$ \\
\hline \multirow{3}{*}{0} & 8 & 269.81 & 2840.02 & 297.69 & 2856.99 & 283.15 & 2820.24 \\
\hline & 16 & 471.55 & 2461.09 & 557.59 & 2516.19 & 508.04 & 2500.18 \\
\hline & 24 & 782.25 & 2682.59 & 916.71 & 2734.82 & 812.51 & 2683.31 \\
\hline \multirow{3}{*}{20} & 8 & 286.62 & 2788.13 & 310.21 & 3017.63 & 291.07 & 2740.77 \\
\hline & 16 & 511.64 & 2334.12 & 560.15 & 2461.17 & 523.21 & 2325.37 \\
\hline & 24 & 837.89 & 2595.69 & 951.61 & 2774.37 & 869.93 & 2612.41 \\
\hline \multirow{3}{*}{50} & 8 & 320.31 & 2809.65 & 320.31 & 2960.27 & 325.64 & 2897.16 \\
\hline & 16 & 594.03 & 2374.22 & 626.81 & 2655.96 & 611.83 & 2634.92 \\
\hline & 24 & 915.57 & 2699.21 & 966.79 & 2776.55 & 936.04 & 2632.28 \\
\hline
\end{tabular}




\begin{tabular}{l|c|c|c|c|c|c|c}
\hline \multirow{3}{*}{80} & 8 & 334.41 & 3291.36 & 334.41 & 3291.36 & 359.32 & 3389.84 \\
\cline { 2 - 8 } & 16 & 613.23 & 2777.31 & 613.23 & 2764.78 & 663.07 & 2898.03 \\
\cline { 2 - 8 } & 24 & 995.03 & 3132.97 & 1028.33 & 3177.77 & 1035.08 & 3220.54 \\
\hline
\end{tabular}

As shown in Table 2, the highest average MPR was obtained with an ethanol recover rate of $0 \%$. However, $\varepsilon_{\mathrm{T}}$ gradually increased with an increasing ethanol recover rate, because $Q_{\text {EtOH }}$ was significantly higher than $Q_{\mathrm{M}}$ (Table 6). As shown in Table 6, recycle provided a higher $\varepsilon_{\mathrm{T}}$ than reflux, with ab ethanol recover rate of $0 \%$ and $20 \%$, respectively; which is equal to the ethanol recovery rate of $50 \%$, but lower with the ethanol recover rate of $80 \%$. Moreover, similar trends were found in energy yield. This result indicated that recycle would be more feasible with a lower ethanol recover rate. In other cases, for energy production, effluent reflux may be a more suitable for the reuse application of the effluent.

\section{Conclusion}

The integration process facilitates the utilization of a carbon source along with hydrogen, ethanol and methane generated from the 2-CSTRs anaerobic digestion system as biofuels with additional substrate degradation. The performance of the system was evaluated with variable ethanol recovery rates of $0 \%, 20 \%, 50 \%$ and $80 \%$, respectively, at variable OLRs ranging between 8-24 $\mathrm{kgCODm}^{-3} \mathrm{~d}^{-1}$. The maximum HPR of $1.34( \pm 0.7) \mathrm{mol} \mathrm{d}^{-1}$ and the maximum EPR of $0.45( \pm 0.4)$ mol d ${ }^{-1}$ were observed at an OLR of $24 \mathrm{kgCOD} \mathrm{m}^{-3} \mathrm{~d}^{-1}$. In addition, the maximum $\mathrm{HC}$ of 26.17 $( \pm 3.62) \%$ and the maximum EC of $32.43( \pm 3.97) \%$ were obtained at an OLR of $16 \mathrm{kgCOD} \mathrm{m}^{-3} \mathrm{~d}^{-1}$. Linear regression of the collection between HPR and EPR can be expressed as $y=0.3182 x+0.0114$ $\left(r^{2}=0.9853\right)$. The highest MPR of $0.45( \pm 0.07) \mathrm{mol} \mathrm{d}^{-1}$ was obtained at the original OLR of 24 $\mathrm{kgCOD} \mathrm{m} \mathrm{m}^{-3} \mathrm{~d}^{-1}$, with an ethanol recover rate of $0 \%$. Recycle and reflux are the two reuse approaches for effluents in the system for producing greater bioenergy. Recycle provided a higher $\varepsilon_{\mathrm{T}}$ and energy yield than reflux, with an ethanol recovery rate of $0 \%$ and $20 \%$, respectively. This was equal to the ethanol recovery rate of $50 \%$, but lower than the ethanol recovery rate of $80 \%$. This indicates that recycle would be more feasible with lower ethanol recovery rates, and reflux may be more suitable with other kinds of ethanol recovery rates. This study provides a protocol for the use of the 2-CSTRs anaerobic digestion system for biofuel production and substrate degradation. This could effectively improve the efficiency of the anaerobic digestion system.

\section{Acknowledgements}

This work was supported by public welfare research program, National Science Foundation of Heilongjiang Province (Grant No. E201354).

\section{References}

[1] Bockris JO'M. The origin of ideas on a hydrogen economy and its solution to the decay of the environment. Int J Hydrogen Energy 2002; 27:731-40.

[2] Imachi H, Sekiguchi Y, Kamagata Y, Ohashi A, Harada H. Cultivation and in situ detection of a thermophilic bacterium capable of oxidizing propionate in syntrophic association with hydrogenotrophic methanogens in a thermophilic methanogenic granular sludge. Appl. Environ. Microbiol. 2000; 66: 3608-12.

[3] Jung KW, Kim DH, Kim SH, Shin HS. Bioreactor design for continuous dark fermentative hydrogen production. Bioresour Technol 2011; 102: 8612-20.

[4] Jones D, Woods D. Acetone-butanol fermentation revised. Microbiological Rev. 1986; 50: 484-524. 
[5] Lin CY, Lay CH, Sen B, Chu CY, Kumar G, Chen CC, Chang JS. Fermentative hydrogen production from wastewaters: A review and prognosis. Int J Hydrogen Energy 2012; 37: $15632-42$.

[6] O. Pakarinen, P. Kaparaju, J. Rintala. The effect of organic loading rate and retention time on hydrogen production from a methanogenic CSTR. Bioresour Technol 2011; 102: 3353-7.

[7] Ren NQ, Chua H, Chan SY, Tsang YF, Wang YJ, Sin N. Assessing optimal fermentation type for bio-hydrogen production in continuous acidogenic reactors. Bioresour Technol 2007; 98: 1774-80.

[8] Kim SH, Han SK, Shin HS. Optimization of continuous hydrogen fermentation of food wastes as a function of solids retention time independent of hydraulic retention time. Process Biochem. 2008; 43: 213-8.

[9] Jung KW, Kim DH, Shin HS. Continuous fermentative hydrogen production from coffee drinks manufacturing wastewater by applying UASB reactor. Int. J. Hydrogen Energy 2010; 35: 13370-8.

[10] Ren NQ, Li J, Li B, Wang Y, Liu S. Biohydrogen production from molasses by anaerobic fermentation with a pilot-scale bioreactor system. Int J Hydrogen Energy 2006; 31: 2147-57.

[11] Hsiao CL, Chang JJ, Wu JH, Chin WC, Wen FS, Huang CC, et al. Clostridium strain co-cultures for biohydrogen production enhancement from condensed molasses fermentation soluble. Int J Hydrogen Energy 2009; 34: 7138-81.

[12] Han W, Chen H, Jiao AY, Wang ZQ, Li YF, Ren NQ. Biological fermentative hydrogen and ethanol production using continuous stirred tank reactor. Int J Hydrogen Energy 2012; 37: 843-7.

[13] Muhammad Jaffar,Yunzhi Pang,Hairong Yuan,Dexun Zou,Yanping Liu,Baoning Zhu,Rashid Mustafa Korai,Xiujin Li. Wheat straw pretreatment with $\mathrm{KOH}$ for enhancing biomethane production and fertilizer value in anaerobic digestion[J]. Chinese Journal of Chemical Engineering,2016,03:404-409.

[14]Janke,L.,Leite,A.,Wedwitschka,H.,Schmidt,T.,Nikolausz,M.,Stinner,W.Biomethane Production Integrated to the Brazilian Sugarcane Industry:The Case Study of S?o Paulo State[A]. ETA-Florence Renewable Energies.Abstracts of the 22nd European Biomass Conference and Exhibition[C].ETA-Florence Renewable Energies:,2014:1.

[15] Ruihao Chen,Yinzhi Xie, Yaqian Zhou,Jianhua Wang,Hui Wang. Production of hydrogen-rich gas and multi-walled carbon nanotubes from ethanol decomposition over molybdenum modified Ni/MgO catalysts[J]. Journal of Energy Chemistry,2014,02:244-250.

[16]Kanthima Phummala,Tsuyoshi Imai,Alissara Reungsang,Prapaipid Chairattanamanokorn,Masahiko Sekine,Takaya Higuchi,Koichi Yamamoto,Ariyo Kanno. Delignification of disposable wooden chopsticks waste for fermentative hydrogen production by an enriched culture from a hot spring[J]. Journal of Environmental Sciences, 2014,06:1361-1368.

[17] KE Xin,WANG Chun-yong,LI Run-dong,ZHANG Yun. Effects of Oxytetracycline on Methane Production and the Microbial Communities During Anaerobic Digestion of Cow Manure[J]. Journal of Integrative Agriculture,2014,06:1373-1381.

[18] Lu Huang,Xin Wen, Yan Wang,Yongde Zou,Baohua Ma,Xindi Liao,Juanboo Liang,Yinbao Wu. Effect of the chlortetracycline addition method on methane production from the anaerobic digestion of swine wastewater[J]. Journal of Environmental Sciences, 2014,10:2001-2006.

[19] Pankaj K. Rai, S. P. Singh, R.K.Asthana. Biohydrogen production from cheese whey wastewater in a two-step anaerobic process. Appl Biochem Biotechnol, publish on line, 20 December 2012

[20] Nanqi Ren, Wanqian Guo, Xiangjing Wan, Lusi Zhang. Hydrogen energy recovery from high 
strength organic wastewater with ethanol type fermentation using acidogenic EGSB reactor[J]. Journal of Harbin Institute of Technology,2005,06:603-607.

[21] Yu H, Zhu Z, Hu W, Zhang H. Hydrogen production from rice winery wastewater in an up flow anaerobic reactor using mixed anaerobic cultures. Int. J. Hydrogen Energy 2012; 27:59-65.

[22] Wei Han, Hong Chen, Anying Jiao. Biological fermentative hydrogen and ethanol production using continuous stirred tank reactor. International journal of hydrogen energy, 37 ( 2012 ):843-847

[23] Wei Han, Bing Wang, Yan Zhou. Fermentative hydrogen production from molasses wastewater in a continuous mixed immobilized sludge reactor. Bioresource Technology,110

(2012): 219-223

[24] Pleissner D, Lam W.C, Sun Z, Lin C.S.K. Food waste as nutrient source in heterotrophic microalgae cultivation. Bioresour Technol 2013; 137: 139-146.

[25] Wei Han, Da Na Liu, Yi Wen Shi, Jun Hong Tang a, Yong Feng Li, Nan Qi Ren. Biohydrogen production from food waste hydrolysate using continuous mixed immobilized sludge reactors. Bioresour Technol 2015; 180: 54-58.

[26] Yasin N.H.M, Mumtaz T, Hassan M.A, Rahman N.A.A. Food waste and food processing waste for biohydrogen production. J. Environ. Manage 2013; 130: 375-385.

[27] Yajie Li,Salma Tabassum,Zhenjia Zhang. An advanced anaerobic biofilter with effluent recirculation for phenol removal and methane production in treatment of coal gasification wastewater[J]. Journal of Environmental Sciences,2016,09:23-33.

[28] Xian-bo SHI, Wei YAN, Wei WANG, Lian-yu ZHAO, Yi-yin SHAN, Ke YANG. Effect of Microstructure on Hydrogen Induced Cracking Behavior of a HighDeformability Pipeline Steel[J]. Journal of Iron and Steel Research(International),2015,10:.

[29] Wencheng Ma,Hongmei Xin,Dan Zhong,Fengyue Qian,Hongjun Han,Yuan Yuan. Effects of Different States of Fe on Anaerobic Digestion:A Review[J]. Journal of Harbin Institute of Technology,2015,06:69-75.

[30] Antonio Molino,Simeone Chianese,Dino Musmarra. Biomass gasification technology: The state of the art overview[J]. Journal of Energy Chemistry,2016,01:10-25.

[31] Muhammad Jaffar,Yunzhi Pang,Hairong Yuan,Dexun Zou,Yanping Liu,Baoning Zhu,Rashid Mustafa Korai,Xiujin Li. Wheat straw pretreatment with $\mathrm{KOH}$ for enhancing biomethane production and fertilizer value in anaerobic digestion[J]. Chinese Journal of Chemical Engineering,2016,03:404-409.

[32] Keke Xiao,Yan Zhou,Chenghong Guo,Yogananda Maspolim,Wun Jern Ng. Impact of undissociated volatile fatty acids on acidogenesis in a two-phase anaerobic system[J]. Journal of Environmental Sciences,2016,04:196-201.

[33] Baodan Jin,Shuying Wang,Liqun Xing,Baikun Li,Yongzhen Peng. The effect of salinity on waste activated sludge alkaline fermentation and kinetic analysis[J]. Journal of Environmental Sciences,2016,05:80-90.

[34] Bin Dong,Peng Gao,Dong Zhang, Yinguang Chen,Lingling Dai,Xiaohu Dai. A new process to improve short-chain fatty acids and bio-methane generation from waste activated sludge[J]. Journal of Environmental Sciences,2016,05:159-168.

[35] Fan Lü,Xian Xu,Liming Shao,Pinjing He. Importance of storage time in mesophilic anaerobic 
digestion of food waste[J]. Journal of Environmental Sciences,2016,07:76-83.

[36]Chang Liu,Jun Wang,Xiaoyan Ji,Hongliang Qian,Liangliang Huang,Xiaohua Lu. The biomethane producing potential in China: A theoretical and practical estimation[J]. Chinese Journal of Chemical Engineering,2016,07:920-928.

[37] Pan Wu,Guangming Zhang,Jianzheng $\mathrm{Li}$. Mg (2+) improves biomass production from soybean wastewater using purple non-sulfur bacteria[J]. Journal of Environmental Sciences,2015,02:43-46.

[38] Xiaoying Dong,Lijie Shao, Yan Wang,Wei Kou,Yanxin Cao,Dalei Zhang. Biogas by two-stage microbial anaerobic and semi-continuous digestion of Chinese cabbage waste[J]. Chinese Journal of Chemical Engineering,2015,05:847-852.

[39] Qinglian Wu,Wanqian Guo,Shanshan Yang,Haichao Luo,Simai Peng,Nanqi Ren. Effects of Ultrasonic and Acid Pretreatment on Food Waste Disintegration and Volatile Fatty Acid Production[J]. Journal of Harbin Institute of Technology,2015,03:1-6.

[40] Michael Seiffert,Michael Nelles. Concepts for Biomethane Production and Usage[A]. Hefei University、 Heifei Association for Science and Technology、Anhui Society for Environmental Sciences.Proceedings of the 5th International Conference on Environmental Technology and Knowledge Transfer[C].Hefei University、Heifei Association for Science and Technology、 Anhui Society for Environmental Sciences:,2014:5.

[41] Hyeong Kyu Namgung,Hae Young Ahn,JiHyeon Song. Development of a two-phase bioreactor for the biological removal of hydrogen sulfide from biogas[A]. .Proceedings of 2011 2nd International Conference on Advances in Energy Engineering(ICAEE)[C].:,2011:6.

[42] Yongli ZHANG,Qingyu WANG,Kai LIN,Xiaolang CHEN. Treatment of Preserved Wastewater with UASB[A]. Engineering and Industry Technology Institute.Proceedings of 2016 International Symposium on Materials Application and Engineering (SMAE 2016)[C].Engineering and Industry Technology Institute:,2016:6.

[43] Jingwen Yu1,Mingxia Zheng,Tao Tao,Jiane Zuo,Kaijun Wang. Waste activated sludge treatment based on temperature staged and biologically phased anaerobic digestion system[J]. Journal of Environmental Sciences,2013,10:2056-2064. 